\title{
A Chiral van der Waals Material Self-Assembled from the High Symmetry Molecules $\mathrm{C}_{60}$ and $\mathrm{SnI}_{4}$ \\ Daniel B. Straus* and Robert J. Cava* \\ Department of Chemistry, Princeton University, Princeton, NJ 08544 USA \\ *Authors to whom correspondence should be addressed. Email: dstraus@princeton.edu,
} rcava@princeton.edu

\begin{abstract}
The design of new chiral materials usually requires stereoselective organic synthesis to create molecules with chiral centers. Less commonly, achiral molecules can self-assemble into chiral materials, despite the absence of intrinsic molecular chirality. Here, we demonstrate the assembly of high-symmetry molecules into a chiral van der Waals structure by synthesizing crystals of $\mathrm{C}_{60}\left(\mathrm{SnI}_{4}\right)_{2}$ from icosahedral buckminsterfullerene $\left(\mathrm{C}_{60}\right)$ and tetrahedral $\mathrm{SnI}_{4}$ molecules through spontaneous self-assembly. Our results represent the remarkable emergence of chirality from the self-assembly of two of the most highly symmetric molecules, demonstrating that almost any molecular precursor can be considered when designing chiral assemblies.
\end{abstract}

\section{TOC Graphic}

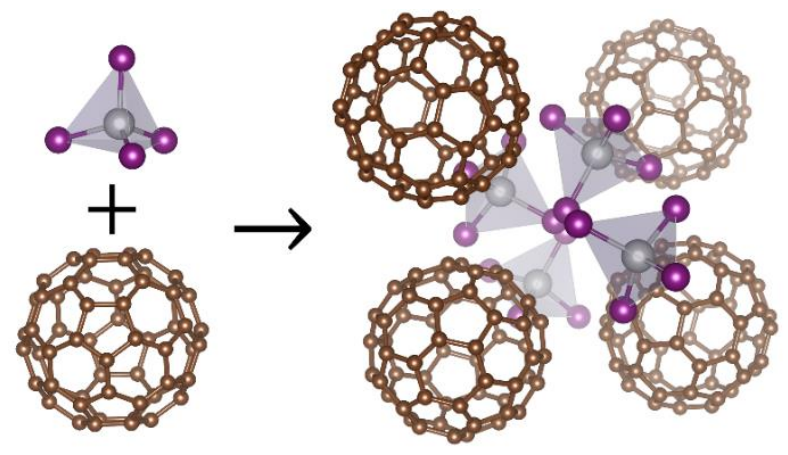


Chiral materials are prized for their unique structural, optical, and catalytic properties. ${ }^{1-6}$ Most chiral materials are molecules synthesized using stereoselective organic synthesis to imprint chirality through the arrangement of atoms. A molecule is chiral if its mirror image is not superimposable on itself, and enantiomerically pure chiral molecules always form chiral crystals. ${ }^{7}$ The chirality of a molecule is maintained even when crystals containing such molecules are dissolved in solution. Another class of chiral materials are three-dimensional covalent or ionic inorganic solids with chiral crystal structures. Examples are the covalent $\alpha$ - and $\beta$-quartz, both of which are intrinsically chiral because of the connectivity of their corner-sharing $\mathrm{SiO}_{4}$ tetrahedra, ${ }^{8}$ as well as the ionic $\mathrm{NaClO}_{3}{ }^{7}$

A third class of chiral materials can occur when achiral molecules self-assemble into a chiral material. These molecules are not bonded to one another and are held together by van der Waals forces, and, when dissolved in solution, the achiral building blocks are recovered and the optical activity of the crystal is lost. ${ }^{7}$ Chiral molecular materials formed from achiral molecules greatly expand the phase-space of optically active species because their chirality is not limited by the connectivity of atoms. The achiral molecules making up these chiral crystals usually contain aromatic substituents and are low symmetry and/or planar compounds. ${ }^{9,10}$ One-component chiral crystals formed from achiral molecules are relatively common and are reported to make up 8\% of the Cambridge Structural Database, ${ }^{10}$ but chiral crystals composed of two or more achiral molecules are scarcely reported. ${ }^{11-15}$

Here we synthesize the chiral van der Waals compound $\mathrm{C}_{60}\left(\mathrm{SnI}_{4}\right)_{2}$ from the highly symmetric achiral molecules $\mathrm{C}_{60}$ and $\mathrm{SnI}_{4}$. High symmetry molecules are considered to be those in the $\mathrm{I}_{\mathrm{h}}$ icosahedral, $\mathrm{O}_{\mathrm{h}}$ octahedral, or $\mathrm{T}_{\mathrm{d}}$ tetrahedral point groups. ${ }^{16}$ One of the molecular constituents of our new compound, $\mathrm{C}_{60}$, is in the $\mathrm{I}_{\mathrm{h}}$ icosahedral point group (Figure 1a), which is 
the highest possible symmetry for a molecule. Further, if a $\mathrm{C}_{60}$ molecule freely rotates in a solid like in $\mathrm{C}_{60}\left(\mathrm{SnI}_{4}\right)_{2}$, it behaves as if it is spherically symmetric. ${ }^{17}$ At room temperature where the $\mathrm{C}_{60}$ molecules freely rotate, $\mathrm{C}_{60}$ itself crystallizes in an achiral centrosymmetric face-centered cubic (FCC) structure, and below $260 \mathrm{~K}$, where the rotation of $\mathrm{C}_{60}$ is frozen, the material undergoes a phase transition to a lower-symmetry but still achiral centrosymmetric simple cubic structure. ${ }^{18-20}$ The other molecular constituent of our new compound is $\mathrm{SnI}_{4}$, which crystallizes as a molecular solid in an achiral centrosymmetric simple cubic structure where each $\mathrm{SnI}_{4}$ molecule is in the $\mathrm{T}_{\mathrm{d}}$ tetrahedral point group (Figure 1b). ${ }^{21}$ Surprisingly, we find that $\mathrm{C}_{60}\left(\mathrm{SnI}_{4}\right)_{2}$ self-assembles in the chiral enantiomorphic cubic space group $\mathrm{P} 4_{3} 32$ (\#212), which is intrinsically chiral because it has a 43 -screw axis. Based on our extensive analysis of the Cambridge Structural Database, we believe $\mathrm{C}_{60}\left(\mathrm{SnI}_{4}\right)_{2}$ is the first chiral van der Waals crystal assembled from two or more neutral components that each have $\mathrm{T}_{\mathrm{d}}$ or greater symmetry. The emergence of chirality from the combination of these highly symmetric achiral molecules expands the collection of molecules known to self-assemble into multi-component chiral structures.

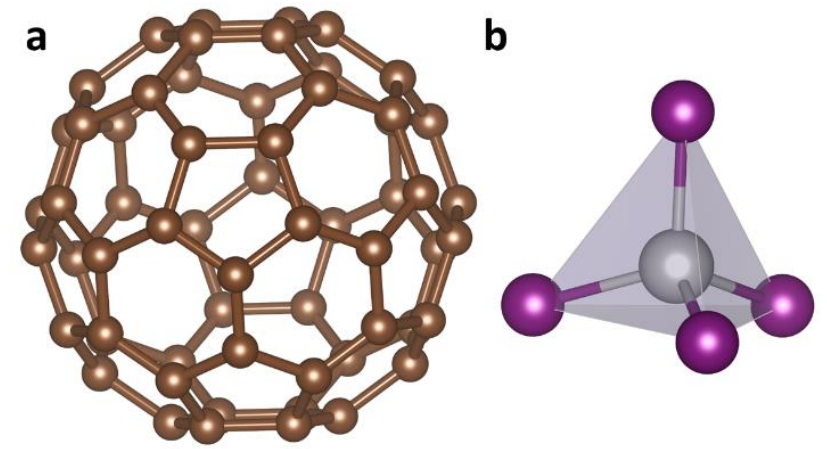

Figure 1: Molecular constituents of $\mathbf{C}_{60}\left(\mathrm{SnI}_{4}\right)_{2}$ : Individual molecules of (a) $\mathrm{C}_{60}$ and (b) $\mathrm{SnI}_{4}{ }^{18,21}$

$\mathrm{C}_{60}$ and $\mathrm{SnI}_{4}$ are both molecular solids, where van der Waals forces hold the molecules together in their crystal structures. $\mathrm{C}_{60}$ and $\mathrm{SnI}_{4}$ co-crystallize to yield the buckminsterfullerene 
intercalation compound $\mathrm{C}_{60}\left(\mathrm{SnI}_{4}\right)_{2}$, which is a van der Waals compound like its crystalline parent materials. $\mathrm{C}_{60}\left(\mathrm{SnI}_{4}\right)_{2}$ crystallizes in the chiral enantiomorphic cubic space group $\mathrm{P}_{3} 32$ (\#212) (Figure 2a and Table 1). The chiral 43 screw axis is highlighted in Figure 2b. $\mathrm{C}_{60}\left(\mathrm{SnI}_{4}\right)_{2}$ adopts the $\mathrm{SrSi}_{2}$ structure type (Figure 2c). One of the two independent iodine atoms resolves with disorder and has refined occupancies of 0.752(9) and 0.248(9). This disorder is omitted for clarity in Figure 2a-b; the structure with disorder and the asymmetric unit are shown in Figure S1. While the Sn and I atoms have well-behaved atomic displacement parameters (ADPs), the C atoms have nearly two-dimensional oblate and prolate ADPs. Abnormal ADPs usually indicate a problem with the structural model, but here they are expected because the $\mathrm{C}$ atoms are constrained to the surface of the $\mathrm{C}_{60}$ ball which we hypothesize is rotating within the crystal like in pure $\mathrm{C}_{60}$ at room temperature. ${ }^{17}$ The shortest $\mathrm{C}_{60}$ center-to-center distance in $\mathrm{C}_{60}\left(\mathrm{SnI}_{4}\right)_{2}$ is $10.14 \AA$, which is only slightly larger than the $10.02 \AA$ distance in room temperature FCC $\mathrm{C}_{60}{ }^{22}$ However, in $\mathrm{C}_{60}\left(\mathrm{SnI}_{4}\right)_{2}$ each $\mathrm{C}_{60}$ only has six nearest neighbors compared to twelve in $\mathrm{FCC} \mathrm{C}_{60}$; the $\mathrm{C}_{60}$ frameworks in $\mathrm{C}_{60}\left(\mathrm{SnI}_{4}\right)_{2}$ and $\mathrm{FCC} \mathrm{C}_{60}$ are shown in Figure $\mathrm{S} 2$. Thermogravimetric analysis (TGA) of a single crystal (Figure S3) indicates $63 \%$ of the mass is lost when heated above $225{ }^{\circ} \mathrm{C}$, consistent with a loss of two $\mathrm{SnI}_{4}$ molecules which comprise $63.5 \%$ of the mass of $\mathrm{C}_{60}\left(\mathrm{SnI}_{4}\right)_{2}$. It is possible that in some preparations single crystals of $\mathrm{C}_{60}\left(\mathrm{SnI}_{4}\right)_{2}$ may crystallize in the space group P4132 (\#213), which is the enantiomer of $\mathrm{P} 4332$ (\#212). 

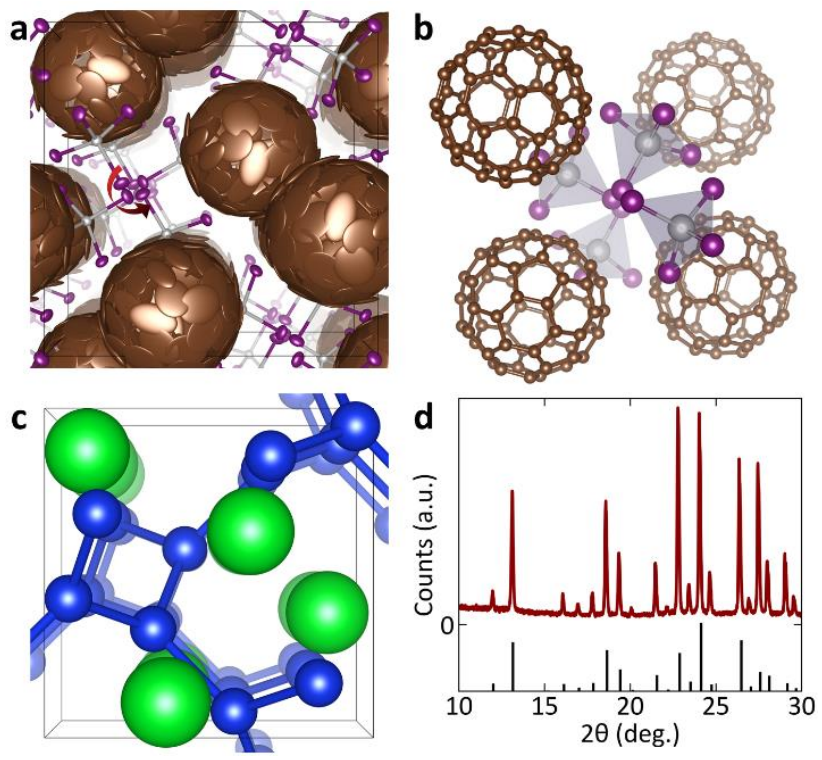

Figure 2: Structural characterization. (a) Structure of $\mathrm{C}_{60}\left(\mathrm{SnI}_{4}\right)_{2}$ with the chiral $4_{3}$ screw axis indicated by red arrow and atoms represented as $50 \%$ probability thermal ellipsoids. (b) detail of chiral 43 screw axis. (c) Structure of $\mathrm{SrSi}_{2}{ }^{23}$ (d) X-ray diffraction pattern of $\mathrm{C}_{60}\left(\mathrm{SnI}_{4}\right)_{2}$ synthesized by a solid-state method (dark red) with simulated powder diffraction pattern from single crystal structure (black).

Table 1: Crystallographic Collection and Structural Parameters

\begin{tabular}{|c|c|}
\hline Empirical formula & $\mathrm{C}_{60} \mathrm{Sn}_{2} \mathrm{I}_{8}$ \\
\hline Formula weight & 1973.18 \\
\hline Temperature (K) & 295 \\
\hline Crystal system & cubic \\
\hline Space group & $\mathrm{P} 4{ }_{3} 32(\# 212)$ \\
\hline a (A) & $16.5593(6)$ \\
\hline Volume $\left(\AA^{3}\right)$ & $4540.7(5)$ \\
\hline $\mathbf{Z}$ & 4 \\
\hline pcalc $\left(\mathrm{g} / \mathrm{cm}^{3}\right)$ & 2.886 \\
\hline$\mu\left(\mathrm{mm}^{-1}\right)$ & 6.585 \\
\hline$F(000)$ & 3536 \\
\hline Crystal size $\left(\mathrm{mm}^{3}\right)$ & $0.31 \times 0.301 \times 0.164$ \\
\hline Radiation & $\operatorname{Mo~K\alpha }(\lambda=0.71073 \AA)$ \\
\hline 20 range for data collection $\left({ }^{\circ}\right)$ & 3.478 to 59.152 \\
\hline Index ranges & $-19 \leq h \leq 12,-8 \leq k \leq 22,-21 \leq \mathrm{I} \leq 12$ \\
\hline Reflections collected & 8784 \\
\hline Independent reflections & $2132\left[R_{\text {int }}=0.0228, R_{\text {sigma }}=0.0246\right]$ \\
\hline Data/restraints/parameters & $2132 / 80 / 88$ \\
\hline Goodness-of-fit on $F^{2}$ & 1.067 \\
\hline Final $R$ indexes $[I>=2 \sigma(I)]$ & $R_{1}=0.0405, w R_{2}=0.0957$ \\
\hline Final $\mathbf{R}$ indexes [all data] & $\mathrm{R}_{1}=0.0518, w \mathrm{R}_{2}=0.1012$ \\
\hline
\end{tabular}




\section{Largest diff. peak/hole $\left(\mathrm{e} \AA^{-3}\right) \quad 0.85 /-0.70$ \\ Flack parameter \\ $-0.08(3)$}

$\mathrm{C}_{60}\left(\mathrm{SnI}_{4}\right)_{2}$ can also be synthesized directly by heating $\mathrm{C}_{60}$ with an excess of $\mathrm{SnI}_{4}$ (to ensure that all $\mathrm{C}_{60}$ reacts) in an evacuated quartz tube and subsequently subliming away the excess $\mathrm{SnI}_{4}$. Direct synthesis in the solid-state results in the formation of a powder rather than single crystals, and the X-ray diffraction pattern of the powder is shown in dark red in Figure $2 \mathrm{~d}$ with a simulated pattern from the single crystal structure in black. No excess $\mathrm{SnI}_{4}$ is observed in the pattern. TGA on the powder reveals the presence of an additional $10 \%$ of $\mathrm{SnI}_{4}$ compared to the crystals, resulting in an empirical formula of $\mathrm{C}_{60}\left(\mathrm{SnI}_{4}\right)_{2.2}$ (Figure $\mathrm{S} 4$ ), which could be the result of excess $\mathrm{SnI}_{4}$ not incorporated into the crystal structure even though it is not observed in the diffraction pattern.

Upon cooling below $260 \mathrm{~K}$, a reversible phase transition occurs. We follow this transition crystallographically by observing the appearance of reflections that are systematically absent in $\mathrm{P}_{3} 32$ (Figure 3). Pure $\mathrm{C}_{60}$ also undergoes a phase transition upon cooling below 255-260 K where the $\mathrm{C}_{60}$ molecules rotationally order, resulting in a change from a FCC to a primitive cubic structure. ${ }^{19,20}$ Given the nearly identical temperatures of the phase transitions in $\mathrm{C}_{60}$ and $\mathrm{C}_{60}\left(\mathrm{SnI}_{4}\right)_{2}$, we hypothesize that a similar rotational ordering of $\mathrm{C}_{60}$ occurs in $\mathrm{C}_{60}\left(\mathrm{SnI}_{4}\right)_{2}$, which breaks the 43 screw axis because the $\mathrm{C}_{60}$ molecules no longer behave as spherical shells and become inequivalent by symmetry. However, we are unable to solve the structure of $\mathrm{C}_{60}\left(\mathrm{SnI}_{4}\right)_{2}$ below $260 \mathrm{~K}$ because of twinning, which is indicated at $100 \mathrm{~K}$ by the $\left|E^{2}-1\right|$ statistic of 0.555 (compared to 0.541 for a perfectly twinned acentric crystal) as well as the cumulative intensity distribution (Figure S5). ${ }^{24,25}$ Determination of the low temperature crystal structure is beyond the scope of the current study. 


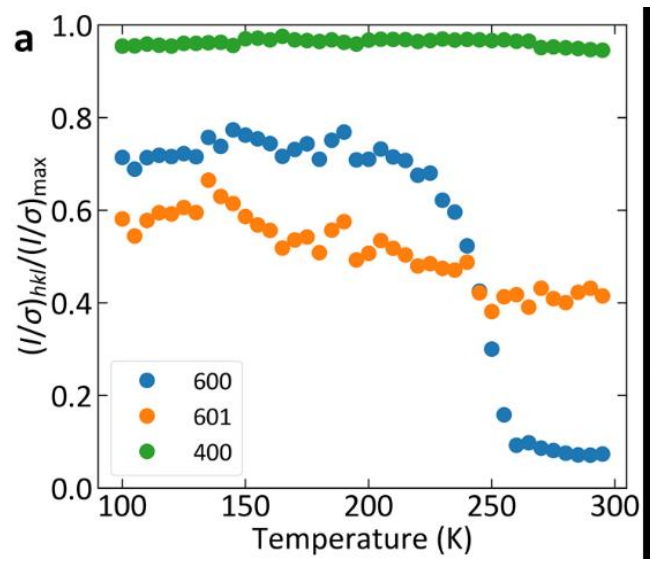

Figure 3: Phase transition. (a) Temperature-dependent intensity of selected allowed ((601) and (400)) and systematically absent (600) reflections. Synthesized precession images of h0l plane at (b) $295 \mathrm{~K}$ and (c) $100 \mathrm{~K}$. White boxes highlight systematically absent reflections (h00 = 0k0 = $001 \neq 4 \mathrm{n}$ ) at $295 \mathrm{~K}$ that appear prominently at temperatures below $260 \mathrm{~K}$.

Optically, $\mathrm{C}_{60}\left(\mathrm{SnI}_{4}\right)_{2}$ behaves similarly to a combination of pure $\mathrm{C}_{60}$ and $\mathrm{SnI}_{4}$, which is expected because $\mathrm{C}_{60}\left(\mathrm{SnI}_{4}\right)_{2}$ is a van der Waals compound composed of discrete $\mathrm{C}_{60}$ and $\mathrm{SnI}_{4}$ molecules. Raman scattering spectra (Figure 4a) demonstrate that the $\mathrm{C}_{60}$ and $\mathrm{SnI}_{4}$ molecules only weakly interact in $\mathrm{C}_{60}\left(\mathrm{SnI}_{4}\right)_{2}$ because its Raman spectrum is almost identical to the combination of the spectra of pure $\mathrm{C}_{60}$ and $\mathrm{SnI}_{4}$. One notable difference is the region between 475 and $575 \mathrm{~cm}^{-1}$ (Figure 4a, inset). In $\mathrm{C}_{60}$, the $493 \mathrm{~cm}^{-1} \mathrm{ag}$ vibrational mode ${ }^{26}$ is known to shift to higher frequency upon reduction to $\mathrm{C}_{60}{ }^{-}$and to lower frequency upon oxidation to $\mathrm{C}_{60}{ }^{+27}$ and the shift of this mode to lower frequency in $\mathrm{C}_{60}\left(\mathrm{SnI}_{4}\right)_{2}$ suggests that that $\mathrm{C}_{60}$ may be oxidized. Another difference is that a weak peak ${ }^{28}$ observed at $564 \mathrm{~cm}^{-1}$ in $\mathrm{C}_{60}$ shifts to $529 \mathrm{~cm}^{-1}$ in $\mathrm{C}_{60}\left(\mathrm{SnI}_{4}\right)_{2}$. The absorption onset of $\mathrm{C}_{60}\left(\mathrm{SnI}_{4}\right)_{2}$ matches pure $\mathrm{C}_{60}$ near the band edge, further indicating that $\mathrm{C}_{60}$ and $\mathrm{SnI}_{4}$ only weakly interact. Pseudoabsorbance spectra are shown in Figure 4b. Whether synthesized in solution or in the solid-state, $\mathrm{C}_{60}\left(\mathrm{SnI}_{4}\right)_{2}$ has a direct band gap of 1.76(1) $\mathrm{eV}$, almost identical to the $1.74(1) \mathrm{eV}$ band gap we find for pure $\mathrm{C}_{60}$ (Figure $\mathrm{S} 6$ ). Interestingly, $\mathrm{C}_{60}\left(\mathrm{SnI}_{4}\right)_{2}$ has a weak transition around $1.5 \mathrm{eV}$ shown in the inset of Figure $3 \mathrm{~A}$ that is absent in pure $\mathrm{C}_{60}$ and $\mathrm{SnI}_{4}$. It is possible that this is another indication of oxidation of the $\mathrm{C}_{60}$ 
and corresponds to the transition from the $\mathrm{g}_{\mathrm{g}}+\mathrm{h}_{\mathrm{g}}$ to $\mathrm{h}_{\mathrm{u}}$ molecular orbitals of $\mathrm{C}_{60},{ }^{29}$ though this energy is larger than the $1.26 \mathrm{eV}$ one electron oxidation potential of $\mathrm{C}_{60}$ measured in solution by cyclic voltammetry. ${ }^{30}$ Above the band edge, $\mathrm{C}_{60}\left(\mathrm{SnI}_{4}\right)_{2}$ has increased absorption in the range where pure $\mathrm{SnI}_{4}$ absorbs, and the solid-state synthesized sample with an empirical formula $\mathrm{C}_{60}\left(\mathrm{SnI}_{4}\right)_{2.2}$ absorbs more strongly than the solution-synthesized sample, consistent with the presence of additional $\mathrm{SnI}_{4}$. Detailed electronic structure calculations are needed to understand the interaction between $\mathrm{C}_{60}$ and $\mathrm{SnI}_{4}$ molecules in $\mathrm{C}_{60}\left(\mathrm{SnI}_{4}\right)_{2}$.

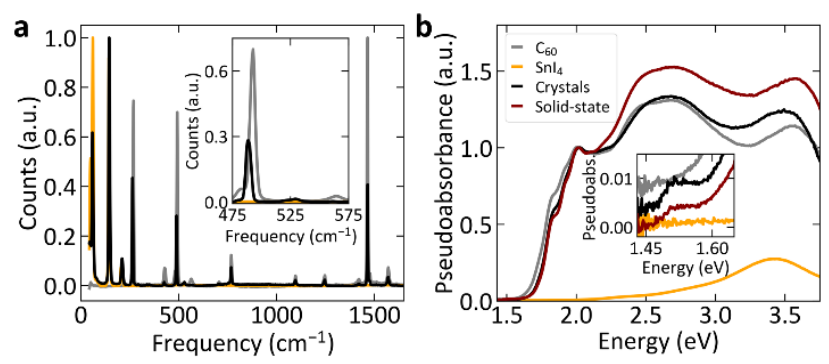

Figure 4: Optical characterization. (a) Raman scattering spectra of $\mathrm{C}_{60}$ (grey), $\mathrm{SnI}_{4}$ (orange), and $\mathrm{C}_{60}\left(\mathrm{SnI}_{4}\right)_{2}$ crystallized from solution (black). (b) Pseudoabsorbance spectra of $\mathrm{C}_{60}$ (grey), $\mathrm{SnI}_{4}$ (orange), and $\mathrm{C}_{60}\left(\mathrm{SnI}_{4}\right)_{2}$ crystallized from solution (black) and synthesized in the solid-state (dark red).

The synthesis of $\mathrm{C}_{60}\left(\mathrm{SnI}_{4}\right)_{2}$ indicates that highly symmetric achiral molecules can crystallize into multi-component chiral van der Waals structures by self-assembly. While the $\mathrm{C}_{60}$ and $\mathrm{SnI}_{4}$ components maintain their discrete molecular character, shifts in the energy of vibrational modes and the appearance of a sub-band gap optical transition in $\mathrm{C}_{60}\left(\mathrm{SnI}_{4}\right)_{2}$ suggest that $\mathrm{C}_{60}$ may be slightly oxidized, indicating a small degree of charge transfer from $\mathrm{C}_{60}$ to $\mathrm{SnI}_{4}$. This discovery expands the library of molecules that can be used to form multi-component chiral assemblies, laying the framework for the design and creation of novel optical and catalytic materials formed by the self-assembly of high-symmetry molecular precursors. 


\section{Methods}

In a typical crystallization, $\mathrm{C}_{60}\left(\mathrm{SnI}_{4}\right)_{2}$ is grown in solution by dissolving $20 \mathrm{mg} \mathrm{C}_{60}$ (BuckyUSA, >99.5\%) and $1000 \mathrm{mg} \mathrm{SnI}_{4}$ (Alfa-Aesar, >95\%) in $40 \mathrm{~mL}$ 1,2-dichlorobenzene (Acros Organics, 99\%). $200 \mathrm{~mL}$ of pentane (Sigma-Aldrich, 98\%) is carefully layered on top of the 1,2-dichlorobenzene solution and the jar is sealed and left undisturbed for several weeks while the two layers mix. Two crystal habits form: black hexagonal crystals of $\mathrm{C}_{60}\left(\mathrm{SnI}_{4}\right)_{2}$ at the bottom of the jar, and black needle-like crystals on the sides of the jar which have a unit cell corresponding to the $\mathrm{C}_{60}$-pentane intercalation compound $\mathrm{C}_{60}\left(\mathrm{C}_{5} \mathrm{H}_{12}\right) .{ }^{31}$ The amount of $\mathrm{C}_{60}\left(\mathrm{C}_{5} \mathrm{H}_{12}\right)$ that crystallizes can be reduced by layering a small amount of benzene on top of 1,2dichlorobenzene before layering pentane.

Bulk $\mathrm{C}_{60}\left(\mathrm{SnI}_{4}\right)_{2}$ is synthesized in the solid-state by sealing $\mathrm{C}_{60}$ and $\mathrm{SnI}_{4}$ in a 1:4 molar ratio in an evacuated quartz tube and heating at $250{ }^{\circ} \mathrm{C}$ for 12 hours followed by cooling to room temperature at $3{ }^{\circ} \mathrm{C} / \mathrm{h}$. Excess $\mathrm{SnI}_{4}$ is used to ensure all of the $\mathrm{C}_{60}$ reacts. Unreacted $\mathrm{SnI}_{4}$ is observed in the X-ray diffraction pattern, so the material is purified two times by sealing in an evacuated quartz tube, heating to $250{ }^{\circ} \mathrm{C}$, and cooling to room temperature at $15^{\circ} \mathrm{C} / \mathrm{h}$ to sublime off the excess $\mathrm{SnI}_{4}$.

Crystals are mounted on Kapton MicroLoops (MiTiGen) with Parabar 10312 oil. Single crystal X-ray diffraction data are collected using a Bruker Kappa Apex2 CCD diffractometer using graphite-monochromated Mo Ka radiation with an Oxford Cryostream 700 cryocooler flowing temperature-controlled nitrogen over the crystal. COSMO (Bruker AXS) is used to determine the data collection strategy. Reflections are integrated using SAINT (Bruker AXS), and SADABS (Bruker AXS) scales the data and applies the multi-scan absorption correction. 
The P4332 space group (\#212) is identified through systematic absences using XPREP (Bruker AXS).

The initial solution to the single crystal structure at $295 \mathrm{~K}$ is found using the intrinsic phasing method in the SHELXT program, ${ }^{32}$ and the structure is refined using the least-squares algorithm in the SHELXL program ${ }^{33}$ in the OLEX2 GUI. ${ }^{34}$ The absolute configuration of the structure is determined using the anomalous dispersion. The occupancies of the disordered iodine atom I2A and I2B freely refine but are constrained to sum to unity and their ADPs are constrained to be equal using the EADP instruction in SHELXL. The $\mathrm{C}_{60}$ molecule is refined by importing the idealized $\mathrm{C}_{60}$ molecule from the Molecular Structure Library ${ }^{35}$ and removing all C atoms that are not needed for the asymmetric unit. The geometry of the $\mathrm{C}_{60}$ asymmetric unit is restrained using the AFIX 9 instruction, and C-C distances in the six-membered rings adjacent to the asymmetric unit in the grown structure are restrained using the SADI instruction to regularize the $\mathrm{C}_{60}$ molecule. The ADPs of the $\mathrm{C}$ atoms are restrained with the DELU instruction. Visualizations of all structures are created using VESTA. ${ }^{36}$

Powder X-ray diffraction data are collected on a Bruker D8 Advance Eco diffractometer in Bragg-Brentano geometry using $\mathrm{Cu} \mathrm{K} \alpha$ radiation with a LYNXEYE 1D strip detector. TGA is conducted using a TA Instruments SDT Q600 under flowing argon. Diffuse reflectance spectra are collected using an Agilent Cary 5000 UV-Vis-NIR absorption spectrometer with an Agilent Internal DRA-2500 diffuse reflectance accessory. Materials are diluted to 2-5\% w/w with dry $\mathrm{MgO}$, and dry $\mathrm{MgO}$ is used as the reflectance standard. Pseudoabsorbance spectra are generated from diffuse reflectance spectra using the Kubelka-Munk function. ${ }^{37}$ Raman scattering spectra are collected using a Thermo-Fisher DXR Smart Raman spectrometer equipped with a $780 \mathrm{~nm}$ HP laser. 


\section{Supporting Information}

The Supporting Information is available free of charge at [PLACEHOLDER]

Single crystal X-ray crystallographic data have been deposited at the Cambridge

Crystallographic Data Centre under deposition number CCDC 1997295 and can be accessed at https://www.ccdc.cam.ac.uk/structures/ as well as in the Supporting Information (CIF)

Figures S1-S5: Additional structural depictions, TGA, cumulative intensity distributions of single crystal X-ray diffraction data, band gap determination (PDF)

\section{Acknowledgments}

We thank Dr. Robert A. Pascal for helpful discussion on chiral crystal structures. This work is supported by the Gordon and Betty Moore Foundation under grant GBMF-4412.

\section{References}

(1) Kitaev, V. Chiral Nanoscale Building Blocks-from Understanding to Applications. J. Mater. Chem. 2008, 18, 4745.

(2) Song, C. E.; Lee, S. G. Supported Chiral Catalysts on Inorganic Materials. Chem. Rev. 2002, 102, 3495-3524.

(3) Adams, J. B.; Filice, A. L. Spectral Reflectance 0.4 to 2.0 Microns of Silicate Rock Powders. J. Geophys. Res. 1967, 72, 5705-5715.

(4) Soai, K.; Osanai, S.; Kadowaki, K.; Yonekubo, S.; Shibata, T.; Sato, I. D - and 1 -QuartzPromoted Highly Enantioselective Synthesis of a Chiral Organic Compound. J. Am. Chem. Soc. 1999, 121, 11235-11236.

(5) Smerdon, J. A.; Rankin, R. B.; Greeley, J. P.; Guisinger, N. P.; Guest, J. R. Chiral "Pinwheel" Heterojunctions Self-Assembled from C 60 and Pentacene. ACS Nano 2013, 7, 3086-3094.

(6) Xu, B.; Tao, C.; Cullen, W. G.; Reutt-Robey, J. E.; Williams, E. D. Chiral Symmetry Breaking in Two-Dimensional C 60 - ACA Intermixed Systems. Nano Lett. 2005, 5, 2207-2211. 
(7) Flack, H. D. Chiral and Achiral Crystal Structures. Helv. Chim. Acta 2003, 86, 905-921.

(8) Tucker, M. G.; Keen, D. A.; Dove, M. T. A Detailed Structural Characterization of Quartz on Heating through the $\alpha-\beta$ Phase Transition. Mineral. Mag. 2001, 65, 489-507.

(9) Liu, M.; Zhang, L.; Wang, T. Supramolecular Chirality in Self-Assembled Systems. Chem. Rev. 2015, 115, 7304-7397.

(10) Matsuura, T.; Koshima, H. Introduction to Chiral Crystallization of Achiral Organic Compounds: Spontaneous Generation of Chirality. J. Photochem. Photobiol. C Photochem. Rev. 2005, 6, 7-24.

(11) Tan, T. F.; Han, J.; Pang, M. L.; Song, H. Bin; Ma, Y. X.; Meng, J. Ben. Achiral Benzoic Acid Derivatives as Chiral Cocrystal Building Blocks in Supramolecular Chemistry: Adducts with Organic Amines. Cryst. Growth Des. 2006, 6, 1186-1193.

(12) Koshima, H.; Miyauchi, M. Polymorphs of a Cocrystal with Achiral and Chiral Structures Prepared by Pseudoseeding: Tryptamine/Hydrocinnamic Acid. Cryst. Growth Des. 2001, $1,355-357$.

(13) Koshima, H.; Nakagawa, T.; Matsuura, T.; Miyamoto, H.; Toda, F. Synthesis, Structure, and Discrimination of Chiral Bimolecular Crystals by Using Diphenylacetic Acid and Aza Aromatic Compounds. J. Org. Chem. 1997, 62, 6322-6325.

(14) Koshima, H.; Matsuura, T. Chiral Bimolecular Crystallization of Achiral Molecules. Mol. Cryst. Liq. Cryst. Sci. Technol. Sect. A Mol. Cryst. Liq. Cryst. 1998, 313, 65-74.

(15) Koshima, H.; Matsuura, T. Chiral Crystallization of Achiral Organic Compounds. Generation of Chirality without Chiral Environment. (Part 2). J. Synth. Org. Chem. Japan 1998, 56, 466-477.

(16) Rassat, A. Chirality and Symmetry Aspects of Spheroarenes, Including Fullerenes. Chirality 2001, 13, 395-402.

(17) Fischer, J. E.; Heiney, P. A.; McGhie, A. R.; Romanow, W. J.; Denenstein, A. M.; McCauley, J. P.; Smith III, A. B. Compressibility of Solid C60. Science 1991, 252, 12881290 .

(18) David, W. I. F.; Ibberson, R. M.; Matthewman, J. C.; Prassides, K.; Dennis, T. J. S.; Hare, J. P.; Kroto, H. W.; Taylor, R.; Walton, D. R. M. Crystal Structure and Bonding of Ordered C60. Nature 1991, 353, 147-149.

(19) David, W. I. F.; Ibberson, R. M.; Dennis, T. J. S.; Hare, J. P.; Prassides, K. Structural Phase Transitions in the Fullerene C 60. Europhys. Lett. 1992, 18, 735-736.

(20) Heiney, P. A. Structure, Dynamics and Ordering Transition of Solid C60. J. Phys. Chem. Solids 1992, 53, 1333-1352. 
(21) Dickinson, R. G. The Crystal Structure of Tin Tetra-Iodide. J. Am. Chem. Soc. 1923, 45, 958-962.

(22) Fischer, J. E. Structure and Dynamics of Solid C60 and Its Intercalation Compounds. Mater. Sci. Eng. B 1993, 19, 90-99.

(23) Evers, J. Transformation of Three-Dimensional Three-Connected Silicon Nets in SrSi2. J. Solid State Chem. 1978, 24, 199-207.

(24) Yeates, T. O.; Tsai, Y. Detecting Twinning by Merohedry. In International Tables for Crystallography Vol. F; Arnold, E., Himmel, D. M., Rossmann, M. G., Eds.; International Union of Crystallography: Chester, England, 2012; pp 311-316.

(25) Dauter, Z. Twinned Crystals and Anomalous Phasing. Acta Crystallogr. - Sect. D Biol. Crystallogr. 2003, 59, 2004-2016.

(26) Eklund, P. C.; Ping, Z.; Kai-An, W.; Dresselhaus, G.; Dresselhaus, M. S. Optical Phonon Modes in Solid and Doped C60. J. Phys. Chem. Solids 1992, 53, 1391-1413.

(27) Fulara, J.; Jakobi, M.; Maier, J. P. Electronic and Infrared Spectra of C+60 and C-60 in Neon and Argon Matrices. Chem. Phys. Lett. 1993, 211, 227-234.

(28) Dennis, T. J.; Hare, J. P.; Kroto, H. W.; Taylor, R.; Walton, D. R. M.; Hendra, P. J. The Vibrational Raman Spectra of C60 and C70. Spectrochim. Acta Part A Mol. Spectrosc. 1991, 47, 1289-1292.

(29) Haddon, R. C. Electronic Structure, Conductivity and Superconductivity of Alkali Metal Doped C60. Acc. Chem. Res. 1992, 25, 127-133.

(30) Xie, Q.; Arias, F.; Echegoyen, L. Electrochemically-Reversible, Single-Electron Oxidation of C60 and C70. J. Am. Chem. Soc. 1993, 115, 9818-9819.

(31) Chancellor, C. J.; Bowles, F. L.; Franco, J. U.; Pham, D. M.; Rivera, M.; Sarina, E. A.; Ghiassi, K. B.; Balch, A. L.; Olmstead, M. M. Single-Crystal X-Ray Diffraction Studies of Solvated Crystals of C 60 Reveal the Intermolecular Interactions between the Component Molecules. J. Phys. Chem. A 2018, 122, 9626-9636.

(32) Sheldrick, G. M. SHELXT - Integrated Space-Group and Crystal-Structure Determination. Acta Crystallogr. Sect. A Found. Adv. 2015, 71, 3-8.

(33) Sheldrick, G. M. Crystal Structure Refinement with SHELXL . Acta Crystallogr. Sect. C Struct. Chem. 2015, 71, 3-8.

(34) Dolomanov, O. V.; Bourhis, L. J.; Gildea, R. J.; Howard, J. A. K.; Puschmann, H. OLEX2 : A Complete Structure Solution, Refinement and Analysis Program. J. Appl. Crystallogr. 2009, 42, 339-341.

(35) Guzei, I. A. An Idealized Molecular Geometry Library for Refinement of Poorly Behaved 
Molecular Fragments with Constraints. J. Appl. Crystallogr. 2014, 47, 806-809.

(36) Momma, K.; Izumi, F. VESTA 3 for Three-Dimensional Visualization of Crystal, Volumetric and Morphology Data. J. Appl. Crystallogr. 2011, 44, 1272-1276.

(37) Hecht, H. G. The Interpretation of Diffuse Reflectance Spectra. J. Res. Natl. Bur. Stand. Sect. A Phys. Chem. 1976, 80A, 567. 
Supporting Information: A Chiral van der Waals Material Self-Assembled from the High Symmetry Molecules $\mathrm{C}_{60}$ and $\mathrm{SnI}_{4}$

Daniel B. Straus* and Robert J. Cava*

Department of Chemistry, Princeton University, Princeton, NJ 08544 USA

*Authors to whom correspondence should be addressed. Email: dstraus@ princeton.edu, rcava@princeton.edu

\section{Additional Figures}
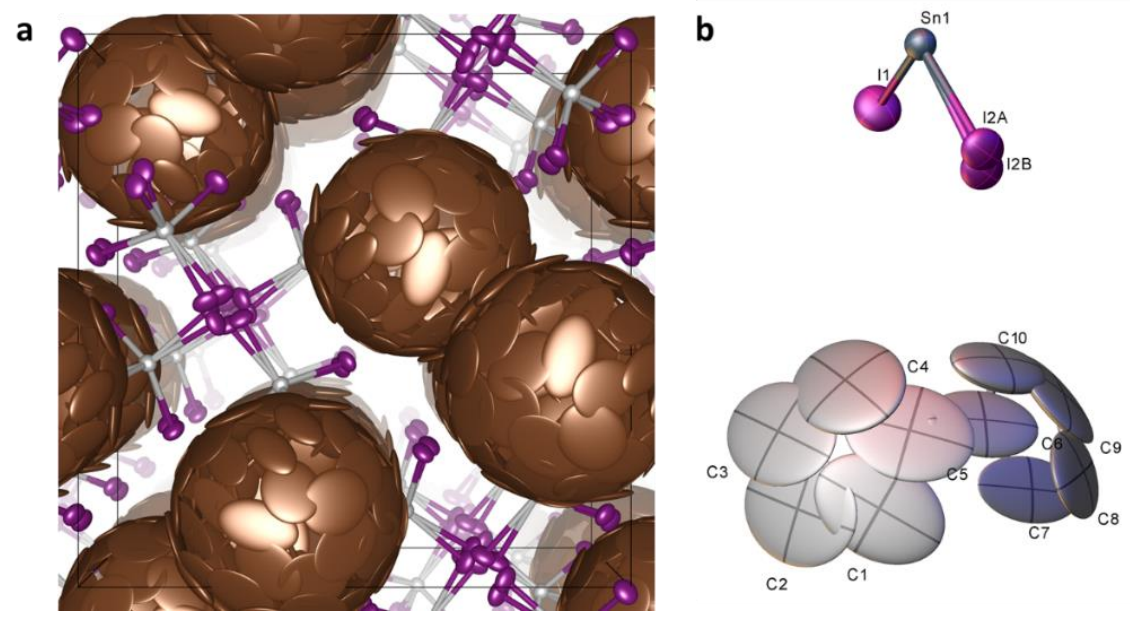

Figure S1: (a) $\mathrm{C}_{60}\left(\mathrm{SnI}_{4}\right)_{2}$ with both disordered I atoms, and (b) asymmetric unit. Atoms are represented as $50 \%$ probability thermal ellipsoids. (B) created using OLEX2.
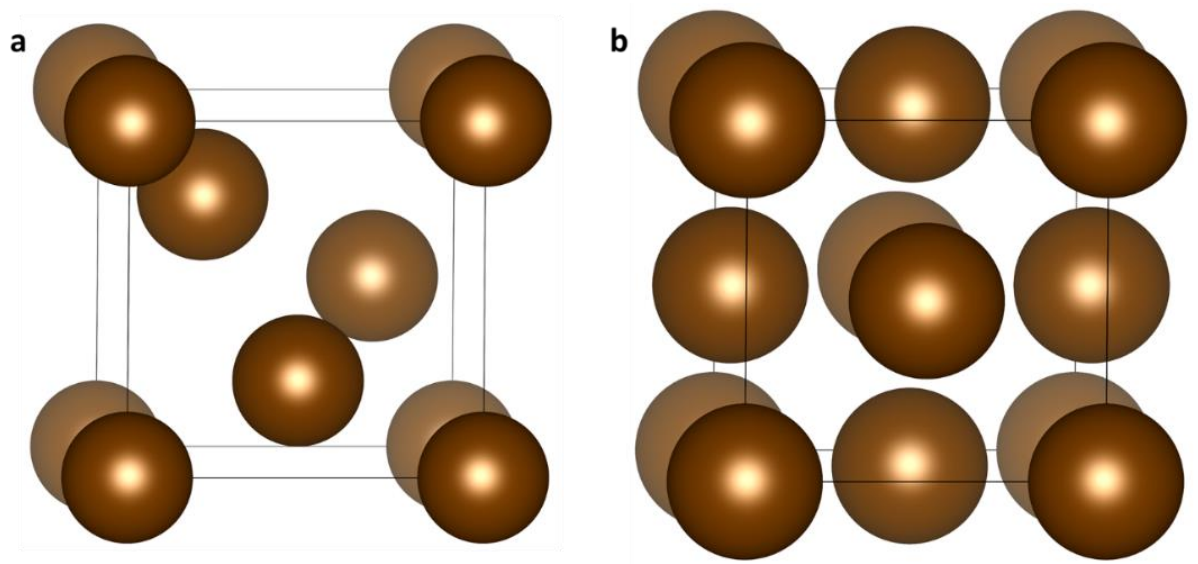

Figure S2: (a) The $\mathrm{C}_{60}$ atoms in $\mathrm{C}_{60}\left(\mathrm{SnI}_{4}\right)_{2}$ represented as spheres. The origin of the unit cell is shifted by $(1 / 8,1 / 8,1 / 8)$ to locate a $\mathrm{C}_{60}$ at each corner. (b) The $\mathrm{C}_{60}$ atoms in FCC $\mathrm{C}_{60}$ represented as spheres. 


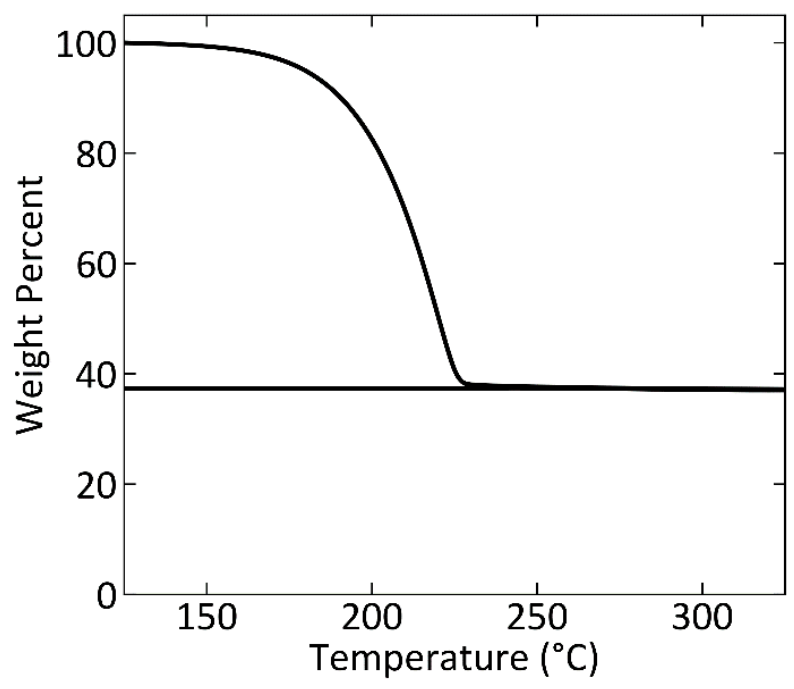

Figure S3: TGA of $\mathrm{C}_{60}\left(\mathrm{SnI}_{4}\right)_{2}$ single crystal heated at $0.5{ }^{\circ} \mathrm{C} / \mathrm{min}$.

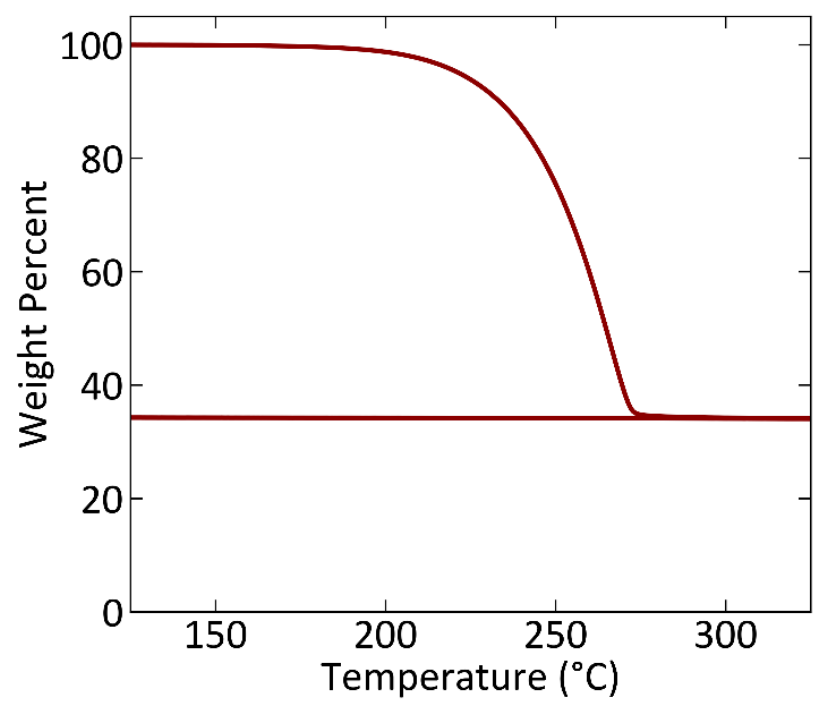

Figure S4: TGA of $\mathrm{C}_{60}\left(\mathrm{SnI}_{4}\right)_{2}$ powder from solid-state synthesis heated at $10{ }^{\circ} \mathrm{C} / \mathrm{min}$. 


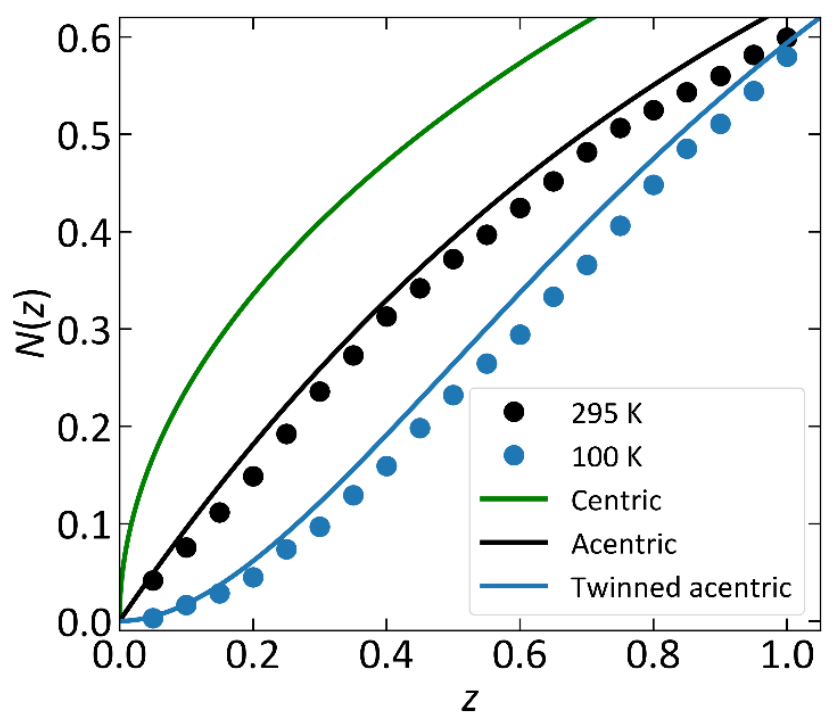

Figure S5: Cumulative intensity distribution for single crystal X-ray diffraction data at $295 \mathrm{~K}$ (black circles) and $100 \mathrm{~K}$ (blue circles) with ideal distributions for centric (green line), acentric (black line), and twinned acentric (blue line) crystals.
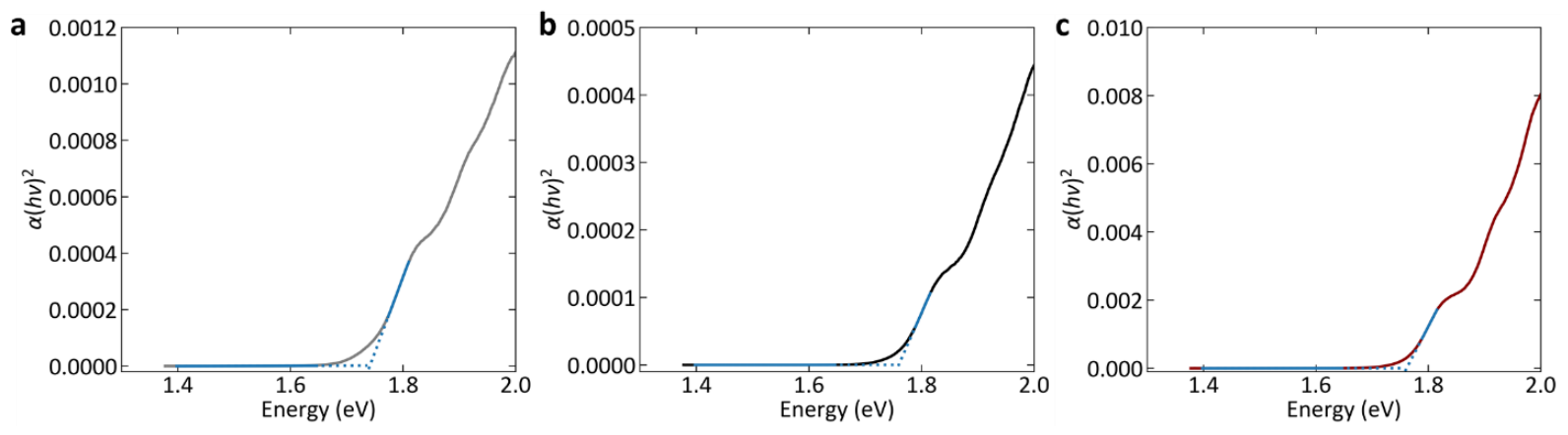

Figure S6: Tauc plots of (a) $\mathrm{C}_{60}$ and $\mathrm{C}_{60}\left(\mathrm{SnI}_{4}\right)_{2}$ synthesized (b) in solution and (c) in the solidstate. 